\title{
Putting technology in its place
}

\section{Why don't Europeans carry Mayan calendar calculators in their Filofaxes?}

\section{Don Ihde}

$\mathrm{R}$ ecently, multicultural and nonlinear accounts of scientific discovery and technological innovation have challenged the dominant linear, often eurocentric histories of science. It has become commonplace to acknowledge that the mathematical concept of zero originated in India, the magnetic compass was developed in China; and even moveable type came from Korea - all before they appeared in Europe.

But it has been harder to recognize nonEuropean attainments as sometimes superior, and even harder to understand the barriers to intercultural transfers. Mesoamericans, for example, developed complex and accurate calendars, implying sophisticated measurements and observations. The Mayans even created a calendar calculator (in stone!) that was more accurate than contemporary European calendars - the Mayans did not need the Gregorian Reform which eliminated 11 days of 1572. The device that did the Long Count was not even recognized as a calendar until centuries after the Spanish Conquest. But the Mayan calendar has never been transferred. The reasons are easy enough to discern - technological devices are embedded in levels of contextual meanings, apart from which they are merely 'objects'.

The Mayan calendar calculator is embedded in a base- 20 mathematics, a celestial cycle of 18,980 days, and a dating system that runs for four days. For the calendar to be read, a whole system of mathematics would have had to have been transferred. At a higher cultural level, calendars are needed to fix socially important events with regularity: Nile floods for the Egyptians; solstice for the Romans; Easter for Christians; and the regularities of the War Star (Venus) for the Mayans. Without an exchange of cultural significations, Mayan cultural meaning would also be difficult to transfer.

The magnetic compass has a long and complex multicultural history, but by the time it had been europeanized, it was but one instrument in a complex set of mathematical methods for mapping longitude and latitude, from which the navigator could tell where he or she was. Puluwateans, one of many South Pacific cultures, could determine their location by means of wave patterns, flights of birds, refractional effects from islands, and so on. The Puluwateans adapted the compass, largely as a fascinating object. But it could only be used to steer a straight course, and this placed the Puluwatean navigator in danger of losing the skills by which one steered a straight course using regular wave patterns. The invention transferred, but the replacement of cultural context had negative results. The compass, moving from one culture to another, became something else.

A reverse transfer from the South Pacific back to Europe also occurred, but belatedly. Captain James Cook, during his famous expeditions of the eighteenth century, recognized the superior speeds, manoeuvrability and seaworthiness of the large Polynesian catamarans (some of which were as long as European vessels), yet multihull design was not adopted in the West until much later. This was probably due to the European need to carry heavy cargo (and cannons), something inimical to high-speed multihull design. And resistance also lay in the inability to transfer techniques from one society's builders to another. When Nathaniel Herreshof, the most notable nineteenth-century American sailing designer, did produce a few racing catamarans, they were quickly declared illegal by the racing clubs, as the innovation threatened the entire racing tradition. Today's multihull sailing

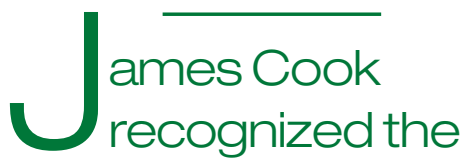

\section{superior speed and}

\section{seaworthiness of the}

Polynesian catamaran. vessels have decimated all previous sail racing records, and high-speed catamaran ferries ply the world's waters.

By recognizing that a technology or an instrument is what it is in relation to its context of meanings, it becomes possible to take deeper account of the problem of recognition itself. The mostly recent and anachronistic interpretations of ancient astronomical instruments - for example, the range of claims interpreting Stonehenge, sighting tunnels in Mexico, and a whole range of related artefacts - as measurement devices, may be as much a reflection of our own obsession with measurement as not.

Nonlinear and multicultural interpretations of the history of science and technology, far from being - as eurocentrists sometimes claim - an opening to relativism, actually recognize the ingenuity of the entire species. The discovery of 800,000-year-old Acheulean-like stone technologies in Asia not only defeats the infamous archaeoracism of the Movius Line (which divided Asia from Europe and Africa; the lack of tools on the Asian side led to the belief that Homo erectus was more conceptually and technologically advanced in Africa and Europe), but pushes humankind's nonlinear, multicultural history further back in time. Contrarily, revisionist and nonlinear interpretations of science and technology are not only more sensitive to, but more respectful of human ingenuity wherever it is found.

Don Ihde is in the Department of Philosophy, State University of New York, Stony Brook, New York 11794-3750, USA.

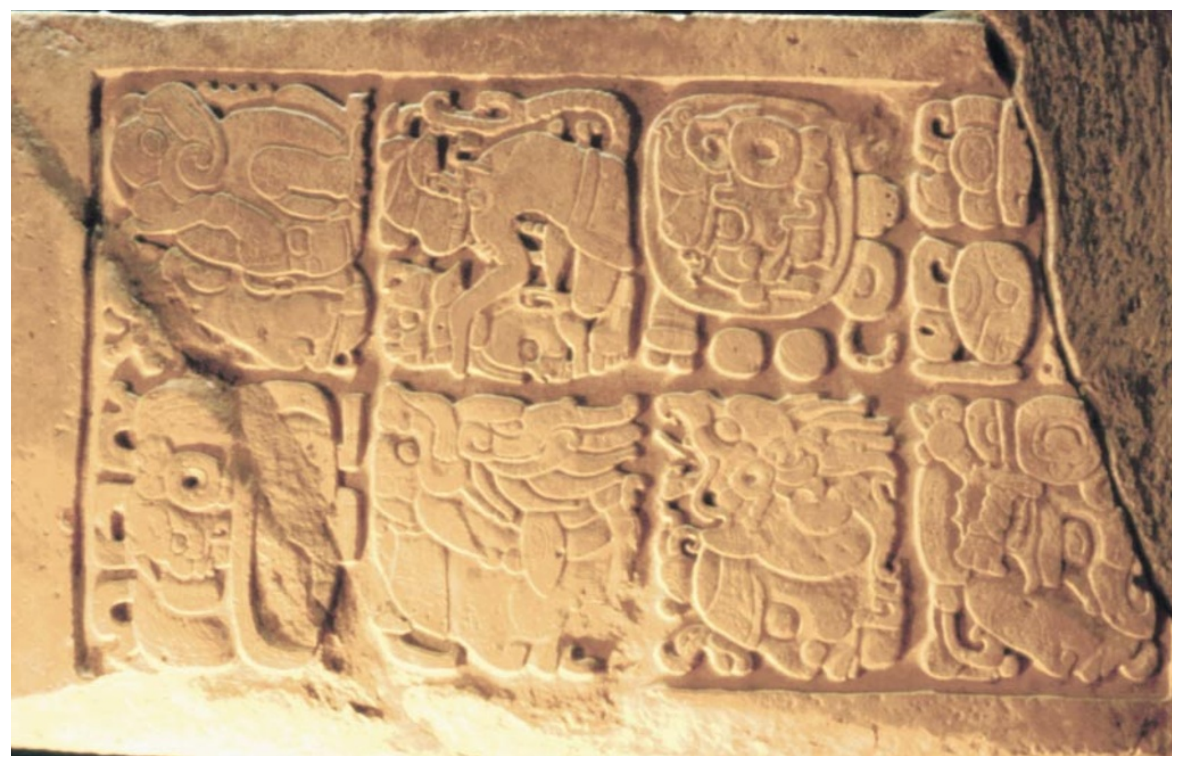

Awkward date: Mayan calendars, such as this one, were more accurate, but used base-20 mathematics. 